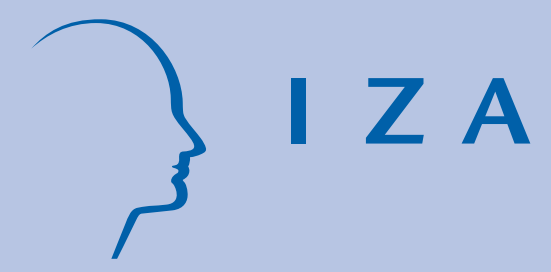

IZA Policy Paper No. 57

The Economic Case for Devoting Public Resources to Health

David E. Bloom

Günther Fink

May 2013 


\title{
The Economic Case for Devoting Public Resources to Health
}

\author{
David E. Bloom \\ Harvard School of Public Health \\ and IZA \\ Günther Fink \\ Harvard School of Public Health
}

\section{Policy Paper No. 57 \\ May 2013}

IZA

P.O. Box 7240

53072 Bonn

Germany

\author{
Phone: +49-228-3894-0 \\ Fax: +49-228-3894-180 \\ E-mail: iza@iza.org
}

The IZA Policy Paper Series publishes work by IZA staff and network members with immediate relevance for policymakers. Any opinions and views on policy expressed are those of the author(s) and not necessarily those of IZA.

The papers often represent preliminary work and are circulated to encourage discussion. Citation of such a paper should account for its provisional character. A revised version may be available directly from the corresponding author. 
IZA Policy Paper No. 57

May 2013

\section{ABSTRACT}

\section{The Economic Case for Devoting Public Resources to Health}

The world has enjoyed huge improvements in population health during the last half century. But major health problems persist, particularly in tropical countries, which are still struggling with infectious diseases while increasingly having to deal with noncommunicable diseases. Several classic arguments for public spending on health have buttressed governments' efforts to improve health. These efforts have now been further spurred by new economic arguments that better population health may promote economic well-being - via beneficial changes in labor productivity, education, and investment, and through demographic change. The economic consequences of improved health can be large, but realizing them depends on the policies adopted in myriad other arenas.

JEL Classification: I15, I14, I18, H51

Keywords: investment in health, labor productivity, education, demographic change, health gaps

Corresponding author:

David E. Bloom

Harvard School of Public Health

Department of Global Health and Population

665 Huntington Avenue

Building I 12th Floor, Suite 1202

Boston, MA 02115

USA

E-mail: dbloom@hsph.harvard.edu 
Global population health has improved significantly in recent decades. Life expectancy has increased in every single country since 1950, with an average increase of 22 years in the period from 1950 to 2010, and a decline in the global under-five mortality rate of two-thirds over the same period. Epidemic polio has ended, the global coverage rate for DTP3 vaccination more than quadrupled between 1980 and 2010, and smallpox, which killed 2 million people a year until the late 1960s, has been wiped out.

Although the overall health improvements are remarkable, substantial health deficits persist in a large number of countries, and the gap between developed and developing countries remains large. The gap is particularly large between tropical and non-tropical countries. ${ }^{1}$ As Table 1 shows, people in the tropical countries live less long, bear more children, and suffer from lower vaccination rates than those in non-tropical countries. They also experience much higher levels of maternal mortality, infant mortality, and under-five mortality. Although the absolute differences between tropical and non-tropical countries have declined for most indicators since 1980, convergence has been slow, and full catch-up appears unlikely within the next few decades.

Table 1 Big health gaps between tropical and non-tropical countries (Average values for various health indicators)

\begin{tabular}{lrrr} 
& & Tropical & $\begin{array}{r}\text { Non- } \\
\text { tropical }\end{array}$ \\
\cline { 3 - 4 } Life expectancy at birth (years) & 1980 & 56.6 & 68.3 \\
\hline Total fertility rate (births per woman) & 1980 & 63.9 & 74.3 \\
\hline Immunization, DPT (\% of children ages 12-23 & 2010 & 5.6 & 3.5 \\
months) & 1980 & 3.6 & 2.1 \\
\hline Maternal mortality ratio (modeled estimate, & 1980 & 39 & 57 \\
per 100,000 live births) & 2010 & $28 . \mathrm{a}$ & 93 \\
\hline Infant mortality rate, (per 1,000 live births) & 1980 & 84 & $\mathrm{n} . \mathrm{a}$ \\
& 2010 & 45 & 55 \\
\hline Under-5 mortality rate (per 1,000 live births) & 1980 & 133 & 58 \\
\hline
\end{tabular}

Note: Averages are unweighted; n.a. indicates "not available".

Source: World Bank, World Development Indicators. Online data, 2012.

One of the primary reasons tropical countries have worse health outcomes than non-tropical countries is their vulnerability to infectious diseases. Table 2 shows the 10 principal causes of death for low- and high-income countries as reported by the World Health Organization (2011). Most of the low-income countries in the WHO sample are tropical, while few of the high-income countries are tropical. As Table 2 shows, six of the top 10 causes of death in low-income countries are infectious diseases, while in high-income countries, only one of the top 10 causes (lower respiratory infections) is an infectious disease.

\footnotetext{
${ }^{1}$ Tropical countries are defined as those with more than half of their land area lying between the Tropic of Cancer and the Tropic of Capricorn. Data are from International Union for Conservation of Nature (1986), http://www.nhm.ac.uk/hosted sites/bbstbg/tropctry.htm, as updated by the author.
} 
Table 2 Infectious diseases still heavily burden tropical countries

(The 10 leading causes of death by broad income group (2008); infectious diseases highlighted)

$\begin{array}{lcr}\text { Low-income countries (40, including } \mathbf{3 4} \text { tropical) } & \text { Deaths in millions } & \text { \% of deaths } \\ \text { Lower respiratory infections } & 1.05 & 11.3 \% \\ \text { Diarrhoeal diseases } & 0.76 & 8.2 \% \\ \text { HIVIAIDS } & 0.72 & 7.8 \% \\ \text { Ischaemic heart disease } & 0.57 & 6.1 \% \\ \text { Malaria } & 0.48 & 5.2 \% \\ \text { Stroke and other cerebrovascular disease } & 0.45 & 4.9 \% \\ \text { Tuberculosis } & 0.40 & 4.3 \% \\ \text { Prematurity and low birth weight } & 0.30 & 3.2 \% \\ \text { Birth asphyxia and birth trauma } & 0.27 & 2.9 \% \\ \text { Neonatal infections } & 0.24 & 2.6 \%\end{array}$

High-income countries (50, including 6 tropical)

Deaths in millions

1.42

0.79

0.54

0.37

0.35

0.32

0.30

0.24

0.21

0.17

\section{$\%$ of deaths}

$15.6 \%$

$8.7 \%$

$5.9 \%$

$4.1 \%$

$3.8 \%$

$3.5 \%$

$3.3 \%$

$2.6 \%$

$2.3 \%$

$1.9 \%$

Breast cancer

Source: World Health Organization Fact sheet N³10, updated June 2011. http://www.who.int/mediacentre/factsheets/fs310/en/index.html

The strong correlation between tropical location and the burden of communicable diseases is also apparent at the regional level. In WHO's "Africa" region (which closely matches what is generally considered to be "Sub-Saharan Africa"), the share of deaths owing to "Communicable diseases, maternal and perinatal conditions and nutritional deficiencies" out of deaths other than injuries is $70 \%$. By contrast, the corresponding share in Europe is $6 \%$.

The simple comparison of disease patterns in tropical versus non-tropical regions is clearly confounded by a large number of country- and region-specific factors such as income, education, and other determinants of health that are partially or entirely unrelated to tropical location. 
While the true causal mechanisms underlying the poor health outcomes in tropical countries are complex and hard to disentangle empirically, it is unquestionable that tropical countries striving for improvements in population health will face major challenges in the coming years. For example, communicable diseases remain the primary concern in most tropical countries, but the rapid global increase in the burden of non-communicable diseases (NCDs) means that governments and health policy makers in tropical countries also get increasingly exposed to new challenges such as diabetes and obesity. This "double burden of disease" poses a major challenge to health systems, since communicable and non-communicable diseases need to be addressed at the same time with limited resources.

A major global shift of attention towards NCDs, as evidenced in part by the September 2011 United Nations High-Level Meeting on NCDs, may also mean that global funding toward communicable diseases may decline and thus put populations in tropical countries at risk.

What can be done to ameliorate the situation? One answer lies in a better understanding of the complex links among health, income, and poverty. This chapter reviews the classic motives for investing in public health and discusses a new argument for doing so: that such investment can yield significant economic benefits. It then reviews the most recent microeconomic and macroeconomic evidence on causal links from health to income. It concludes with thoughts on how policymakers and other stakeholders can use these findings to enable governments to invest in health in a timely, cost-effective, efficient manner - and one that is appropriate for the special needs of tropical countries.

\section{Classic arguments for spending on public health}

There are four traditional lines of arguments in favor of devoting public resources to promoting and protecting health:

- Ethical arguments: Moral, ethical, and humanitarian considerations dictate that allocating resources to the improvement of population health is ethical, just, and a fair course of action.

- Health as a human right: Health is a fundamental human right, which means that the opportunity to enjoy good health is a legally just claim to which all human beings are entitled.

- Health to promote social cohesion and global security: Health is a key ingredient in forming social capital, and better health will help lead to societies that are cohesive, peaceful, equitable, and secure. A nascent political argument that highlights population health as a key determinant of political stability and international security has also been proffered. $^{2}$

\footnotetext{
${ }^{2}$ For example, in a 2000 study commissioned by the CIA (Goldstone, Jack A., et al, "State Failure Task Force Report: Phase III Findings" (http://www.cidcm.umd.edu/publications/papers/SFTF\%20Phase\%20II\%20Report\%20Final.pdf), the global model for predicting state failure finds that "[I]ow levels of material well-being, measured by infant mortality rates", "roughly doubled the odds of state failure". This result is consistent with the view that the inability of a government to satisfy the basic needs of its electorate - including and especially its health erodes trust and may contribute to repeated cycles of instability and collapse. This appears to be one reason why Richard Holbrooke, then-US Ambassador to the United Nations, masterminded the first-ever UN Security Council meeting on health. At that 2000 meeting, US Vice President Gore said that AIDS was a security issue that the world had to address. In addition, in 2010, the UN General Assembly held a
} 
- Health investment to address behavioral externalities: Since individuals may infect others and not fully take into account the health and financial consequences of their actions, private health behavior is likely to be suboptimal from a societal perspective. Therefore, welfare improvements can be achieved through government intervention. Public health expenditure, particularly in the realm of disease prevention, can lead to substantial reductions in the costs of treatment and care, and thus have high financial returns.

All four arguments have been important historically, but none have been decisive in their ability to mobilize resources. While the ethical and moral justifications are undoubtedly powerful in theory, they have not proven to be good arguments to substantially increase government expenditure. Arguments built on the spread of infectious diseases have also not carried the day, as evidenced by the fact that although immunization rates have risen greatly, $15 \%$ of the world's children are still not being vaccinated for DTP. More broadly, roughly $17 \%$ of all deaths under age 5 (and 29\% of deaths between one month and five years) are from vaccine-preventable diseases. $^{3}$

One of the more recent arguments that has generated considerable additional momentum in support of public funding for health in general, and infectious diseases in particular, is the notion that poor health leads to less productive and economically less successful countries. Although the argument has gained considerable traction in recent years, it has a curious history.

\section{Health in traditional macroeconomics}

One of the oldest, most basic, and yet most difficult questions in the field of economics is why some countries are so much richer than others. While many tropical countries have per capita incomes of less than US $\$ 5000$ today, most Western countries have per capita incomes well in excess of US\$30,000. The fundamental question of why income differentials across countries are so large was first posed by the father of modern economics, Adam Smith. In his seminal 1776 treatise, The Wealth of Nations, Smith first highlighted the importance of the division of labor and to labor productivity. Following his original argument, the view that long dominated the field of economics was that income disparities between countries arise from cross-country differences in their stocks of physical capital (tools, plants, equipment, infrastructure like harbors, irrigation systems, communication networks, and natural resources) and their technology. According to this view, national income increases via capital accumulation and technological progress. As countries become more productive, the marginal product of workers increases, causing firms that operate in competitive labor markets to offer higher wages.

meeting on global health and adopted consensus text on "Global Health and Foreign Policy" (UN General Assembly Document A/65/95 http://www.who.int/mental health/policy/resolution global health and foreign policy.pdf). The text "encourages Member States to consider the close relationship between foreign policy and global health", acknowledges "the need to improve research and development in neglected tropical diseases, and welcoming in this regard the first World Health Organization report on neglected tropical diseases", acknowledges "that progress in global health is dependent primarily on national policies and actions and on international cooperation and partnerships, which could help to respond to major global challenges and crises" and urges "Member States to continue to consider health issues in the formulation of foreign policy".

${ }^{3}$ World Health Organization and UNICEF (2012). "Global Immunization Data". http://www.who.int/immunization monitoring/Global Immunization Data.pdf 
With increasing data availability in the second half of the 20th century, this first generation of economic models was challenged by the fact that the cross-country income differences were rather large relative to cross-country differences in capital stock and technology. To address the lack of predictive power of the original model, the notion of capital was augmented to include human capital (in particular, education and skill) in addition to physical or financial resources. ${ }^{4}$ However, even the collective differences in physical capital, technology, and education were insufficient to account for the observed differences in per capita income, and remained so when positive feedback mechanisms from increased income to capital stock, levels of education, and investment in research and development were taken into account. ${ }^{5}$

What role does health have in this literature? Despite the difficulty of accounting for the sources of economic differentials and a large number of attempts to expand existing frameworks, relatively few studies have attempted to directly account for health as a determinant of income in the economic growth literature. ${ }^{6}$ In most traditional work, population health is viewed as a consequence of income growth rather than a determinant of growth.

This one-directional view is well illustrated by Samuel Preston's representation of the changing relationship between income and health. Figure 1 shows an updated version of Preston's formulation for both tropical and non-tropical countries. ${ }^{7}$ Each panel shows the relationship between income per capita and life expectancy in 1980 and 2010. The basic tendency in both panels is for countries with higher per capita incomes to have healthier populations - a pattern that holds for different income and health measures and at different points in time. The scatterplots also reveal that for a given level of income, the life expectancy that a country can achieve increases substantially over time.

This patterns displayed in Figure 1 are suggestive of a causal link that runs from income to health, since health improvements can either be observed through:

- Increases in income per capita (reflected by the tendency of points plotted for 2010 to represent higher income than in 1980, which would indicate higher life expectancy under the positive relationship between health and income prevailing in each year).

- Improvements in health technology, institutions, and infrastructure at the same levels of income (reflected in the upward shift of the curve from 1980 to 2010 for both tropical and non-tropical countries).

\footnotetext{
${ }^{4}$ See, for example, Schultz, Theodore W. (1963), The Economic Value of Education, New York: Columbia University Press.

${ }^{5}$ These ideas are introduced in the literature on endogenous growth. See, for example, Romer, P. (1986).

"Increasing Returns and Long-Run Growth". Journal of Political Economy, Vol. 94, 1002-1037.

${ }^{6}$ Notable exceptions are Bloom, David E., and David Canning (2000). "The Health and Wealth of Nations", Science, Vol. 287, 1207-9; and Shastry and Weil, who show that differences in adult survival explain $19 \%$ of the total (log) variation in income in capita, which corresponds to almost one-third of the variation in output that is left unexplained by other measures of factor accumulation. See Shastry GK, Weil DN (2003). "How Much of Cross-Country Income Variation is Explained by Health?" Journal of the European Economic Association 1: 387-396.

${ }^{7}$ Preston, S. H (1975). "The Changing Relation between Mortality and Level of Economic

Development", Population Studies 29 (2): 231-248.
} 
Figure 1 Life expectancy is highly correlated with per capita income ...

(Preston curves for 1980 and 2010)

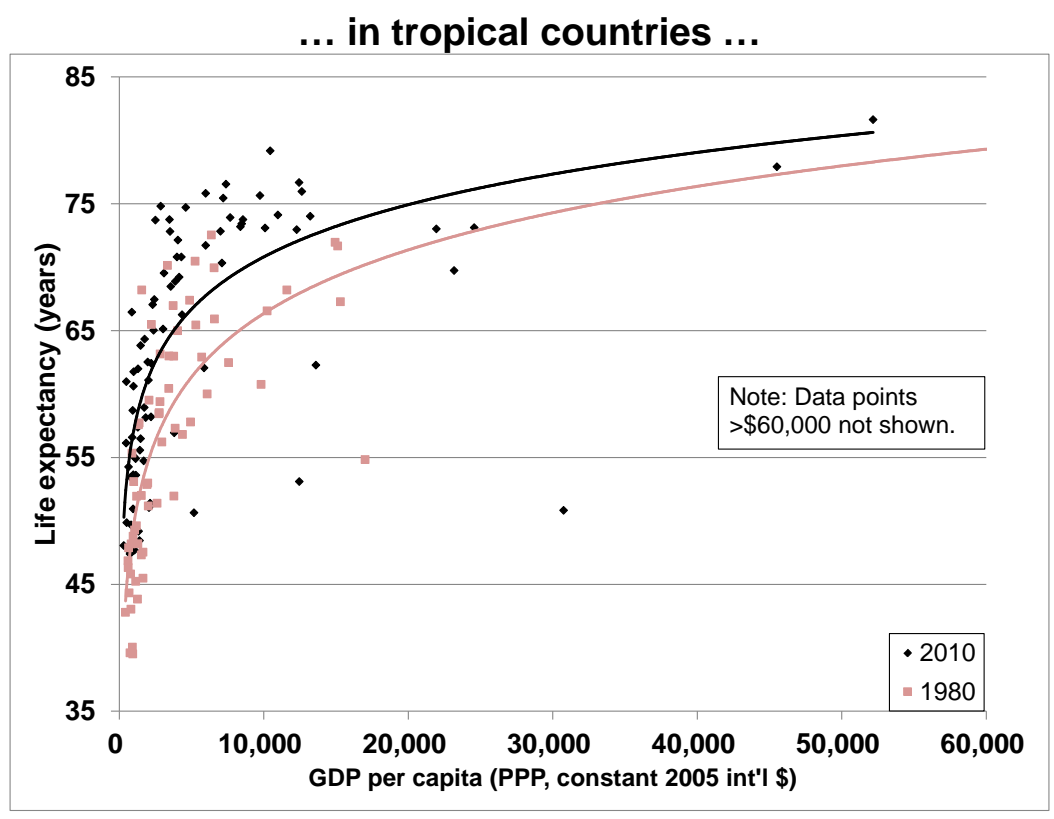

... and in non-tropical countries

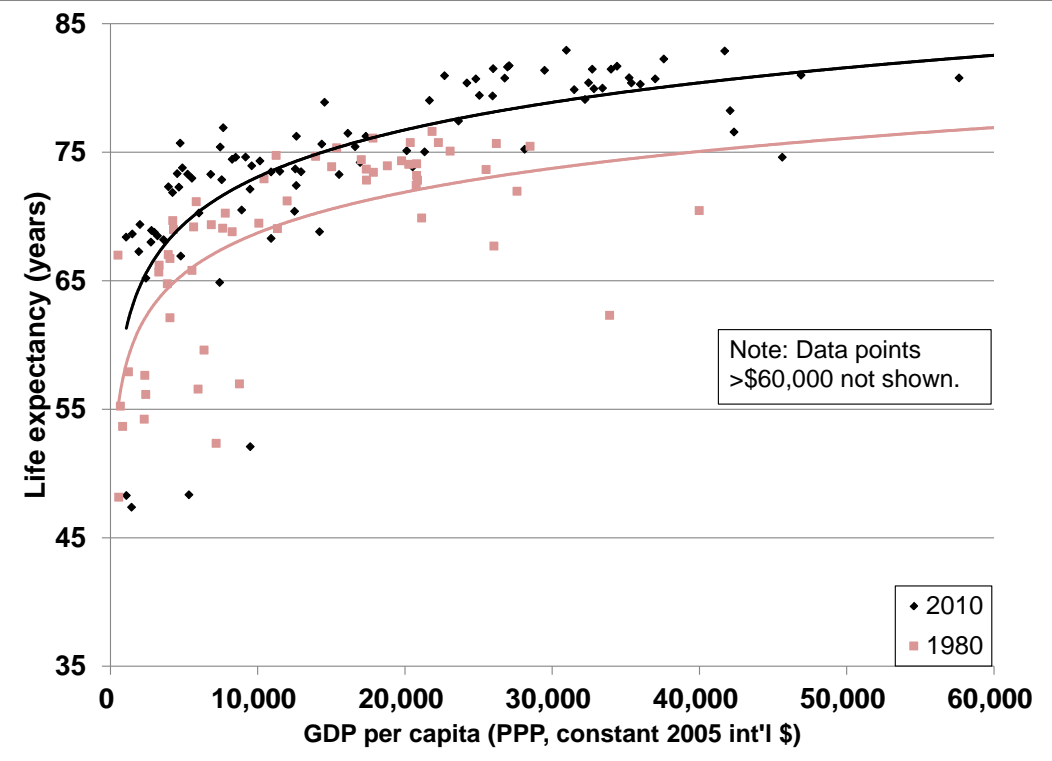

Source: World Bank, World Development Indicators. Online data, 2012.

Decomposition analysis shows that improvements in health technology, institutions, and infrastructure have contributed more to overall health gains than have increases in national incomes. ${ }^{8}$ While this is an important point, it is slightly misleading or at least incomplete, since it fails to consider the possibility that the positive association between health and income also reflects a causal link from health to income. Some reasons why this might be so - related to

${ }^{8}$ Preston, S. H. (1975) op cit. and also reconfirmed by the authors using the data plotted in Figure 1. 
labor productivity, education, investment (including foreign direct investment), and demographic change - are discussed below.

\section{Microeconomic evidence on how better health benefits the economy}

Even though health has played a relatively minor role in traditional models of economic growth, a large number of economic studies have analyzed the important links between health and income at the individual ("microeconomic") level. In her seminal work from 1962, Selma Mushkin ${ }^{9}$ evaluates the relative contribution of changes in the quality of people to economic progress. Her article clarifies the similarities and differences between health and education. It also sets forth numerous ideas about the economic benefits of health and the issues involved in estimating those benefits. Her work was followed by a considerable body of microeconomic research that treated health as a form of human capital, akin to knowledge and skill.

Microeconomic studies have considerable potential to inform both researchers and policy makers about the relationships between health and income. By focusing on individuals rather than countries, microeconomic studies have several methodological advantages: more detailed measures of health and income and their determinants, larger sample size, and the ability to analyze natural or true randomized experiments. ${ }^{10}$ As highlighted in a 2002 review of studies on the links among health, nutrition, and prosperity by Duncan Thomas and Elizabeth Frankenberg ${ }^{11}$, such experimental studies are crucial since they allow a careful identification of key biological and behavioral mechanisms of interest.

In their 1998 review of the existing microeconomic literature in this area, John Strauss and Duncan Thomas $^{12}$ show that the weight of the evidence points strongly toward the existence of a causal impact of health on productivity, employment, and earnings. The review also highlights the contribution of nutrition in childhood to determining adult health and wages. Since then, there have been many compelling micro studies, including a number focused on tropical health. The following section summarizes the main body of work in this area.

\section{Randomized controlled studies}

Deworming. Intestinal worms (helminthes) are a major problem in poorer countries because they can significantly diminish a child's cognitive ability and general health. Ted Miguel and Michael Kremer examined the effects of school-based deworming on educational outcomes in school-age children in Kenya. In a randomized controlled study, the authors find that deworming

\footnotetext{
${ }^{9}$ Selma J. Mushkin (1962), "Health as an investment", Journal of Political Economy, Vol. 70, No. 5, pp. 129-157.

${ }^{10}$ Randomized controlled trials involve three basic steps: (i) randomly divide the experimental population into a treatment group that participates in a potentially beneficial program, and a control group that does not; (ii) assess outcomes of both groups; and (iii) determine whether a significant difference in outcomes exists between the two groups. By contrast, natural experiments occur when a phenomenon (such as an earthquake, a new disease outbreak, or a new policy) induces external variations in individual characteristics that can be explored to investigate the causal impact of the respective characteristic on an outcome of interest.

${ }^{11}$ Thomas, Duncan and Elizabeth Frankenberg (2002), "Health, Nutrition, and Prosperity: A Microeconomic Perspective," Bulletin of the World Health Organization 80 (2): 106-113.

12 John Strauss and Duncan Thomas, 1998. "Health, Nutrition, and Economic Development," Journal of Economic Literature, vol. 36(2), pages 766-817.
} 
led to higher school attendance and provided community-wide benefits. ${ }^{13}$ In a follow-up study, they also found large increases in wages among children growing up in treated areas. ${ }^{14}$

Iron supplements. Along similar lines, but not pertaining to childhood intervention, is the research of Duncan Thomas, Elizabeth Frankenberg, and colleagues that shows the beneficial effect of iron supplementation on productivity and earnings. ${ }^{15}$ Their study is based on a randomized, controlled intervention involving over 17,000 30-70-year-olds in Indonesia. Males who were iron-deficient prior to the intervention, and who received the iron supplements, were "more likely to be working, sleep less, lose less work time to illness, are more energetic, more able to conduct physically arduous activities, and their psycho-social health is better," and they were earning more on both an hourly and monthly basis. There were lower benefits for women, but in the same positive direction as for males.

Iron and deworming. Bobonis, Miguel, and Puri-Sharma examine the effect of a randomized health intervention that delivered iron supplements and deworming drugs to pre-school children in India. ${ }^{16}$ They find significant evidence of weight gain and increased participation in preschool programs.

lodine. Several studies have investigated the impact of iodine supplementation on income. lodine deficiency can impair the formation of the fetal brain and thus reduce cognitive functioning. In one study, Erica Field and colleagues find evidence of a significant positive effect on educational attainment of an iodine distribution program in Tanzania. ${ }^{17}$ They find larger effects for girls than for boys, which is consistent with the results of laboratory research showing that female fetuses are more sensitive than male fetuses to maternal iodine deprivation. These results confirm the quasi-experimental data collected by Politi, Weil, and Feyrer referenced below. ${ }^{18}$

Malaria. Siân Clarke and colleagues use a randomized controlled trial to study the effects on educational outcomes of intermittent treatment for the prevention of malaria in Kenyan schoolchildren. ${ }^{19}$ They find that malaria prevention leads to increased attention scores (which measure children's ability to sit still and pay attention to instruction) and lower child parasitemia at follow-up.

${ }^{13}$ Miguel, Edward, and Michael Kremer (2004). "Worms: identifying impacts on education and health in the presence of treatment externalities", Econometrica, Vol. 72, No. 1, 159-217.

${ }^{14}$ Baird S, Hicks JH, Kremer M, Miguel E (2012) Worms at Work: Long-run Impacts of Child Health Gains. Mimeo. http://scholar.harvard.edu/kremer/files/klps-labor 2012-03-23 clean.pdf

${ }^{15}$ Thomas, Duncan, Elizabeth Frankenberg, et al (2004). "Causal Effect of Health on Labor Market Outcomes: Evidence from a Random Assignment Iron Supplementation Intervention". On-Line Working Paper Series, California Center for Population Research, University of California, Los Angeles, http://escholarship.org/uc/item/1h66k92r;jsessionid=ED8DDE9D7B38785AA80D7293263ED72D\#page-3

${ }^{16}$ Bobonis, Gustavo J., Edward Miguel, and Charu Puri-Sharma (2006). "Anemia and School Participation." Journal of Human Resources 41(4): 692-721.

${ }^{17}$ Field, Erica, Omar Robles, and Maximo Torero (2009). "Iodine Deficiency and Schooling Attainment in Tanzania." American Economic Journal: Applied Economics, 1(4): 140-69.

${ }^{18}$ Politi, Dimitra, David N. Weil, and James Feyrer (2011), "The Economic Effects of Micronutrient Deficiency: Evidence from Salt lodization in the United States," ESE Discussion Papers 201, Edinburgh School of Economics, University of Edinburgh. http://hdl.handle.net/10943/143

${ }^{19}$ Clarke, Siân E, Matthew C H Jukes, J Kiambo Njagi, Lincoln Khasakhala, Bonnie Cundill, Julius Otido, Christopher Crudder, Benson B A Estambale, and Simon Brooker (2008), "Effect of intermittent preventive treatment of malaria on health and education in schoolchildren: a cluster-randomised, doubleblind, placebo-controlled trial", Lancet 372: 127-38. 


\section{Natural or quasi-experimental studies}

Malnutrition. Alderman and colleagues study the effect of malnutrition in pre-school children and find a positive association between early nutrition and both later height (which has widely been found to correlate with earnings) and the amount of schooling completed. ${ }^{20}$ They calculate that the "loss of stature, schooling and potential work experience results in a loss of lifetime earnings of around 14\%."

Hookworm. Hoyt Bleakley conducted a study of hookworm disease in the American South in the early 1900s to evaluate the effect on income and education of the sudden and successful eradication of this disease. ${ }^{21}$ At the time, hookworm infected $40 \%$ of school-age children and caused listlessness, stunting, and anemia - but not mortality. He shows that areas with higher levels of hookworm infection prior to the Rockefeller Sanitary Commission's intervention experienced: (i) greater increases in school attendance after the intervention (a 23\% boost in the likelihood of attendance); (ii) subsequent increases in labor earnings; and (iii) higher rates of return on investments in education, which imply more human capital accumulation per year of schooling.

Iodine. Politi, Weil, and Feyrer explore historical variations in salt iodization in the United States and find a significant positive effect on cognitive function and a significant negative effect on the prevalence of goiter. ${ }^{22}$

Malaria. Bleakley also studied malaria eradication in the American South and parts of Central and South America. ${ }^{23} \mathrm{He}$ finds evidence that the elimination of malaria led to faster increases in both literacy and wages in regions that were malaria-endemic before the intervention.

\section{How better health benefits the economy overall}

Several recent studies suggest that the effects of health at the country level may be larger than the effects observed at the individual level, ${ }^{24}$ a conclusion that reached a wide audience through

\footnotetext{
${ }^{20}$ Alderman, H., J. Hoddinott, and B. Kinsey (2006). "Long term consequences of early childhood malnutrition". Oxford Economic Papers 58 (3), 450-474.

${ }^{21}$ Bleakley, Hoyt (2007), "Disease and Development: Evidence from Hookworm Eradication in the American South", The Quarterly Journal of Economics 122 (1): 73-117.

22 Politi, Dimitra, David N. Weil, and James Feyrer (2011), "The Economic Effects of Micronutrient Deficiency: Evidence from Salt lodization in the United States," ESE Discussion Papers 201, Edinburgh School of Economics, University of Edinburgh. http://hdl.handle.net/10943/143

${ }^{23}$ Bleakley, Hoyt (2010), "Malaria Eradication in the Americas: A Retrospective Analysis of Childhood Exposure", American Economic Journal: Applied Economics, 2(2):1-45.

24 Bloom, David E., and David Canning (2000). "The Health and Wealth of Nations", Science, Vol. 287, 1207-9; Bloom, David E., David Canning and Dean Jamison (2004). "Health, Wealth, and Welfare", Finance \& Development, Vol. 41, No. 1, 10-15; Bloom, David E., David Canning, and Jaypee Sevilla (2004). "The Effect of Health on Economic Growth: A Production Function Approach", World Development, Vol. 32, No. 1, 1-13; Bloom, David E., and Jeffrey Sachs (1998). "Geography, Demography, and Economic Growth in Africa', Brookings Papers on Economic Activity, 1998, Vol. 2, 207-295;
} 
the 2001 report of WHO's Commission on Macroeconomics and Health. ${ }^{25}$ On average, each 10year gain in life expectancy is associated with as much as an additional percentage point of annual growth of income per capita. ${ }^{26}$ In a world economy in which per capita income typically grows at 2-3 percent per year, an additional percentage point is a substantial increase. Even though a 10-year gain in life expectancy may appear large, similar improvements have been frequently reached by several countries in relatively short spans of time.

Another key message is that improved health is central to alleviating poverty. ${ }^{27}$ The main asset poor people possess is their labor, and the value of that asset is crucially determined by their health. This explains why health figures so prominently in plans to halve the global poverty rate between 1990 and 2015 - the first UN Millennium Development Goal. ${ }^{28}$

The powerful associations between health and economic development have spurred research to understand the causal links underlying these connections. Four principal channels have emerged though which health is likely to affect output at the country level: productivity, education, investment, and demographics.

Labor productivity channel. A healthier workforce is characterized by more energy, better mental health, and less absenteeism, and is thus more productive.

\footnotetext{
${ }^{25}$ World Health Organization (2001). "Macroeconomics and Health: Investing in Health for Economic Development". Commission on Macroeconomics and Health.

${ }^{26}$ Bloom, David E., and David Canning (2000). "The Health and Wealth of Nations", Science, Vol. 287, 1207-9; Bloom, David E., David Canning and Dean Jamison (2004). "Health, Wealth, and Welfare", Finance \& Development, Vol. 41, No. 1, 10-15.

${ }^{27}$ Bloom, David E., David Canning, Bryan Graham, and Jaypee Sevilla, "Global Integration and the Reduction of Poverty", in Manuel R. Agosín, David E. Bloom, Georges Chapelier, and Jagdish Saigal, eds., Solving the Riddle of Globalization and Development, Routledge, UK, 2007, 104-123.

${ }^{28}$ There is a notable dissent from the general conclusion linking health improvements to economic growth: a prominent paper by Daron Acemoglu and Simon Johnson (Acemoglu, Daron, and Simon Johnson. "Disease and Development: The Effect of Life Expectancy on Economic Growth." Journal of Political Economy 115, no. 6 (2007): 925-85). Acemoglu and Johnson address some of the difficulties associated with interpreting the results obtained from studying cross-country data by taking note of the huge innovations in health technology that occurred in the 1940s and 1950s with the advent and diffusion of penicillin and other antibiotics, sulfa drugs, and the use of DDT for malaria control. They show that these sudden and unanticipated breakthroughs led to larger health gains in some countries than others, for example, in Africa as compared with Europe. If the "healthier means wealthier" hypothesis is true, they reason, the countries with the largest gains from these medical innovations should have grown faster, other things equal, than countries not particularly exposed to the relevant diseases. They find no evidence of this differential effect on the rate of economic growth and strongly challenge the existence of a health-to-wealth link. But the Acemoglu-Johnson analysis has a problem in that the "potential to benefit" from medical innovation is not independent of health, but rather a reflection of the strength of the country health systems themselves. Countries with excellent health systems in 1940 had less to gain from the studied health innovations, but were still growing fast. After taking account of initial life expectancy, the health-to-wealth link is statistically restored. In other words, Acemoglu and Johnson's conclusion is fragile and not well supported by their own data. For further evidence and discussion, see, for example, Aghion, Philippe, Peter Howitt, and Fabrice Murtin. "The Relationship between Health and Growth: When Lucas Meets Nelson-Phelps," Review of Economics and Institutions 2, no. 1 (2011); Bloom, David E., David Canning, and Günther Fink. "Disease and Development Revisited," Journal of Political Economy, forthcoming 2013.; Cervellati, Matteo, and Uwe Sunde. "Life Expectancy and Economic Growth: The Role of the Demographic Transition," Journal of Economic Growth 16, no. 2 (2011): 99-133; and Lorentzen, Peter, John McMillan, and Romain Wacziarg, "Death and Development." Journal of Economic Growth 13, no. 2 (2008): 81-124.
} 
Education channel. Education is virtually undisputed among economists as being one of the most powerful instruments of income growth. ${ }^{29}$ Health affects education through three fundamental channels: first, by enhancing children's physical ability to attend school; second, by increasing children's cognitive ability to absorb knowledge presented in school ${ }^{30}$, and third, by providing additional incentives for parents to invest in their children's education since the returns on such investment can be expected to be earned over a longer period ${ }^{31}$. A recent study ${ }^{32}$ finds that in "21 OECD countries over the past two centuries ... health has been highly influential for the quantity and quality of schooling, innovations and growth."

Investment channel. Healthy populations have longer life expectancies, and thus increased incentives to save for future consumption needs. In response to greater expected longevity, many people might choose to work until a later age even if public and private pension systems offer disincentives for doing so. A larger domestic savings stock leads to a larger supply of capital, which is presumed to result in further investment, additional physical and human capital, and technological progress - all of which are classic drivers of economic growth. In addition, healthy populations attract foreign direct investment, which often carries with it new technology, job creation, and increased trade. ${ }^{33}$

Demographic channel. Better health triggers a set of demographic changes, known as the "demographic transition," that can ultimately boost economic growth. In fact, there is a growing body of evidence that attributes the "economic miracles" experienced in the Asian Tigers and the Celtic Tiger (Ireland) largely to high rates of growth of factor inputs - labor, physical capital, and human capital - rather than increases in total factor productivity.

The demographic transition typically begins when improvements in health - often spurred by better access to sanitation and safe water and increased use of vaccines and antibiotics trigger a decline in infant and child mortality rates. In high-mortality populations, such declines cause rapid population growth. The initial boom in population strains capital resources and tends to slow the rate of economic growth (as conventionally measured). As couples realize that the mortality environment has changed, fertility declines and population growth gradually slows down.

As the initial baby boom cohort reaches working age and fertility rates decline, the number of dependent individuals (children and old age) per worker declines. On a per capita basis, productive capacity increases. This effect is further reinforced if mothers who spend less time with childbearing and child care participate more in the labor market. Since the working-age group is also the primary contributor to savings, potential output also benefits from increased capital accumulation and subsequent technological innovation. Eventually, the working-age

\footnotetext{
${ }^{29}$ Psacharopoulos, George, and Harry A. Patrinos (2004). "Returns to Investment in Education: A Further Update," Education Economics, 12(2), pp. 111-134.

${ }^{30}$ Grantham-McGregor S, Cheung YB, Cueto S, Glewwe P, Richter L, et al. (2007) Developmental

Potential in the First 5 years for Children in Developing Countries. Lancet 369: 60-70.

${ }^{31}$ Soares RR (2005) Mortality Reductions, Education Attainment, and Fertility Choice. American Economic Review 95: 580-601.

${ }^{32}$ Madsen, Jakob (2012). "Health, Human Capital Formation and Knowledge Production: Two Centuries of International Evidence". NBER Working Paper 18461. http://www.nber.org/papers/w18461

${ }^{33}$ Bloom, David E., David Canning, Rick Mansfield, and Michael Moore (2007). "Demographic Change, Social Security Systems, and Savings", Journal of Monetary Economics 54, 92-114; Alsan, Marcella, David E. Bloom, and David Canning (2006). "The Effect of Population Health on Foreign Direct Investment Inflows to Low- and Middle-Income Countries", World Development, Vol. 34, No. 4, 613-630.
} 
share decreases as the baby boom generation ages and fertility rates converge to a low (replacement) level.

Importantly, during the middle stage of the demographic transition - when the working-age share is high - countries have the opportunity to benefit from what has come to be known as the "demographic dividend" - that is, they can experience a demographically driven, time-limited economic boom if working-age people are productively employed. ${ }^{34}$ One of the best examples of such a boom took place in East Asia, where roughly one-third of that region's economic boom between 1965 and 1990 can be attributed to realization of this demographic dividend.

Where are countries now in this demographic transition? The non-tropical countries, as a whole, have already had the opportunity to benefit economically from the rapidly rising ratio of workingage (aged 15-64) to non-working-age individuals (those under 15 or older than 64). Some countries have experienced a demographic dividend, and some not. Non-tropical countries, as whole, are about to experience a decline in the ratio of their working-age population to their nonworking-age population. Tropical countries, as Figure 2 shows, have been following a similar demographic trajectory, but with a delay of about 20 to 25 years. This means they have not yet reached the "optimal" age structure and are likely to have the opportunity to benefit from demographic change over the next few decades. According to UN demographic projections, fertility rates will decline; however, they will not fall as much as they have in non-tropical countries, so the peak levels of working-age share experienced in non-tropical countries over the past decade are unlikely to be realized in tropical countries.

\footnotetext{
${ }^{34}$ Bloom, David E. (2011), "7 Billion and Counting", Science, Vol. 33 (562), 562-569; Bloom, David E., and David Canning, "Global Demographic Change: Dimensions and Economic Significance" (2008), Population and Development Review, Vol. 33, 17-51; Bloom, David E., and David Canning (2011), "Demographics and Development Policy", Development Outreach, 77-81; Bloom, David E., and Jeffrey Williamson (1998), "Demographic Transitions and Economic Miracles in Emerging Asia", World Bank Economic Review, Vol. 12, No. 3, 419-455.
} 
Figure 2 Tropical countries have begun to replicate the pattern of non-tropical countries (Ratio of working-age to non-working-age population)

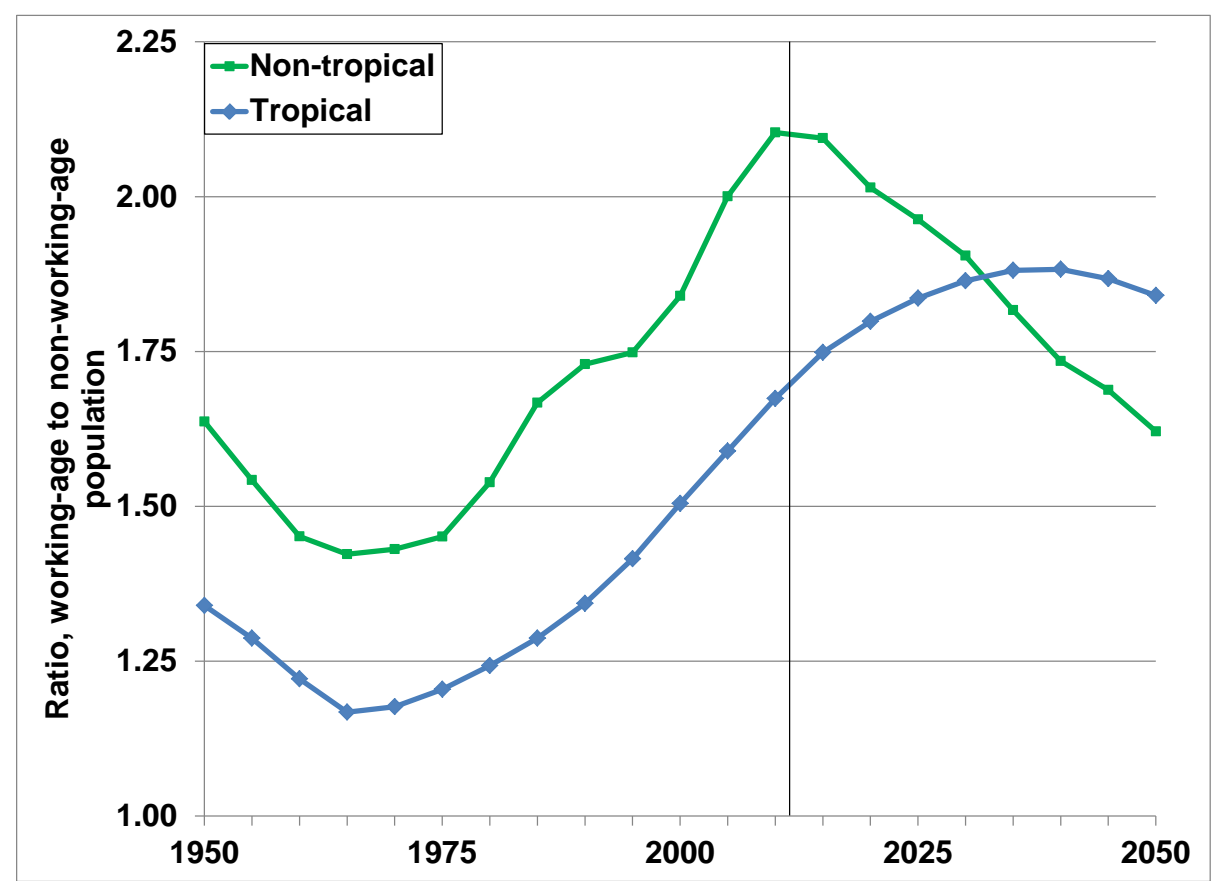

Source: United Nations, World Population Prospects, online data, 2012, and authors' calculations based on list of tropical countries cited above.

\section{Economic effects of specific diseases}

Malaria is the disease most commonly cited in the context of economic growth. Worldwide, there are 500 million episodes of malaria each year, resulting in about 1 million deaths per year. ${ }^{35}$ Malaria has been shown to have an effect on economic growth over and above that created through higher mortality, suggesting that its effects on productivity with a given mortality burden are greater than other diseases. According to a frequently cited paper by Gallup and Sachs, economies with high malaria prevalence in 1965 grew 1.3 percentage points less per year than others between 1965 and 1990, "even after other factors such as initial income level, overall health, and tropical location are taken into account". In terms of the effect on savings and investment, the eradication of malaria in southern Europe in the 1940s and 1950s spurred economic growth in countries like Greece and Spain via a large increase in tourism in them. ${ }^{36}$

As for HIVIAIDS, the disease has increased mortality rates dramatically, but most researchers do not see a direct impact on income per capita.

\footnotetext{
${ }^{35}$ Murray CJL, Rosenfeld LC, Lim SS, Andrews KG, Foreman KJ, et al. (2012) Global malaria mortality between 1980 and 2010: a systematic analysis. The Lancet 379: 413-431.

${ }^{36}$ Gallup, J.L. and J.D. Sachs, 2001, "The economic burden of malaria", American Journal of Tropical Medicine and Hygiene 64 (1, 2 Supplement): 85-96.
} 
- Bloom and Mahal ${ }^{37}$ find that HIVIAIDS does not seem to lower income per capita. Mahal $^{38}$ corroborates this result, as do Werker, Ahuja, and Wendell. ${ }^{39}$ One possible reason is that lower output may be matched by lower population numbers owing to high death rates. Also, during the time frame of these studies, HIVIAIDS had high mortality but the period of sickness before death was relatively short. This mutes the worker productivity effects of the disease; the main effects stem from its impact on demography (that is, a decreased share of working-age people) and the impact of a shortened expected lifespan on life-cycle behavior.

- Bonnel ${ }^{40}$ raises the possibility of a negative impact on growth. He reviews the reasons that HIVIAIDS would be likely to reduce economic growth and finds, in conclusions that he says should be viewed as preliminary, that the empirical results match these expectations: "In the case of a typical sub-Saharan country with a prevalence rate of 20 per cent, the rate of growth of GDP would be some 2.6 percentage points less each year. At the end of a twenty year period GDP would be 67 per cent less than otherwise. One reason for the large impact of HIVIAIDS is that it includes the effect of AIDS-related opportunistic infections and other communicable diseases."

- Young ${ }^{41}$ argues that AIDS in South Africa is likely to increase income per capita, primarily because the reduced human capital available to nurture orphans is offset by lower fertility.

Important indirect mechanisms also exist. Deaths from HIVIAIDS are concentrated among young adult men and women and depend on socioeconomic factors. These selectivity effects could eventually reduce GDP per capita. Bell, Devarajan, and Gersbach ${ }^{42}$ argue that the creation of a generation of AIDS orphans may lead to lack of care and education for children and to low productivity in the future. The high level of stigma associated with HIVIAIDS can reduce trust in the community, while high mortality and the strains imposed by extreme ill health before death can weaken families, community groups, firms, and government agencies, with long-term consequences for social capital (see Haacker ${ }^{43}$ ). Resources devoted to preventing and treating HIVIAIDS can reduce consumption of other goods, so consumption and welfare decline even as measured GDP per capita remains steady.

\section{Policy implications}

What policy-relevant implications can we draw from the ideas discussed?

${ }^{37}$ Bloom, D.E. and A.S. Mahal, 1997, Does the AIDS Epidemic Threaten Economic Growth? Journal of Econometrics 77 (1): 105-24.

${ }^{38}$ Mahal, Ajay (2004). "Economic Implications of Inertia on HIVIAIDS and Benefits of Action," Economic and Political Weekly (March 6), 1049-1063.

${ }^{39}$ Werker, Eric, Amrita Ahuja, and Brian Wendell (2006). "Male Circumcision and HIVIAIDS: The Macroeconomic Impact of a Health Crisis." August. Manuscript.

${ }^{40}$ Bonnel, R., 2000. "HIVIAIDS and Economic Growth: A Global Perspective." South African Journal of Economics 68(5):360-379.

${ }^{41}$ Young, Alwyn (2005). "The Gift of the Dying: The Tragedy of Aids and the Welfare of Future African Generations," Quarterly Journal of Economics, May, 120(2):423-466.

${ }^{42}$ Bell, C., S. Devarajan, and H. Gersbach, 2004, Thinking About the Long-Run Economic Costs of AIDS, in M. Haacker (ed.), The Macroeconomics of HIVIAIDS, Washington DC, International Monetary Fund.

${ }^{43}$ Haacker, M., 2004, HIVIAIDS: The Impact on the Social Fabric and the Economy, in M. Haacker (ed.), The Macroeconomics of HIVIAIDS, Washington DC, International Monetary Fund. 
First, health spending is appropriately regarded as an investment in income growth. Health is both an indicator and an instrument of development. As such, health spending is comparable to spending on education, infrastructure, and good governance as a determinant of economic well-being.

Second, health-income spirals can be virtuous or vicious. The framework described above suggests strong feedback mechanisms between health and income. In an ideal scenario, improvements in health lead to income growth, which can lead to further improvements in health and incomes. The East Asian experience is a good example of this, with simultaneous and rapid increases in economic growth and health. By the same token, this framework also raises the possibility of vicious spirals, in which shocks, such as the HIVIAIDS epidemic, can depress income, which in turn can depress health status and further deteriorate income.

Third, the overall economic returns on investment in health appear large. Immunization against infectious disease is a prime example. Vaccinated children tend to avoid the long-term sequelae associated with certain childhood diseases, such as neurological impairments, hearing loss, and a variety of other physical disabilities, and they therefore tend to be more productive workers when they grow up. Parents and grandparents of vaccinated children tend to be healthier themselves and can thus work more productively, bringing broader economic benefits to society as a whole. Rough calculations indicate that, taking into account all of the benefits of vaccination, the rate of return on investments in vaccination programs is at least as large as estimated rates of return on investments in primary school (an investment widely acknowledged to be one of the most fruitful possible). This logic and these kinds of calculations will be more important than ever in the future, because policy makers now have to make spending decisions about a new generation of much more expensive vaccinations - including those against rotavirus, pneumococcal disease, and human papilloma virus. More broadly: Improved health is not only associated with faster economic growth at the country level, but has also been shown to increase a society's productive capacity by increasing child development, education, and savings.

Fourth, better health improves well-being through lower fertility rates. In societies benefiting from good population health, the expectation that children will grow up healthy naturally leads to families having fewer children. Fewer children means a lower burden of youth dependency, a more educated young generation, and a larger female workforce, which fuels the demographic dividend referred to earlier - an outcome that has been instrumental to many economies in spurring economic growth and reducing poverty. These demographic change processes can be powerfully enabled and further accelerated through sustained family planning programs.

Fifth, good population health is not automatically translated into economic well-being. Cuba and Sri Lanka, as well as the Indian state of Kerala, are examples of countries or areas in which populations are healthy but poor. The Soviet Union, too, raised the level of its population's health, but its economic achievements were more mixed. In all situations, a consistent and enabling policy environment is key to realizing the economic benefits that better health can bring. This means sound macroeconomic policies and practices, carefully constructed trade policy, good governance, high-quality education that reaches a high proportion of school-age individuals, and effective labor market practices. A combination of these can lead to economically productive employment, in which people's efforts benefit not only themselves but also the country as a whole. These elements of the policy environment are, of course, important regardless of demographics. But the incentive to adopt and implement 
them is particularly high in tropical countries that have yet to complete their demographic and health transitions, because the potential benefits are particularly large at this stage of development. Correspondingly, failure to provide an efficient enabling environment can lead to a demographically-driven disaster, in which large working-age cohorts are unemployed, with concomitant risks of social and political instability.

Finally, a large number of diverse interventions can induce and support improvements in population health. A large medical literature focuses on ways to improve health by improving the availability and quality of health services, including the delivery of specific treatments and vaccines. However, in many other cases, the most effective ways to improve population health may be reduce exposure to specific diseases. This may in some cases be achieved through simple behavioral change campaigns, and in other cases through larger infrastructure projects, such as water and sanitation networks. Many other interventions and policies, such as improved schooling, will also have important positive effects even though they may not directly be considered part of larger health efforts.

\section{Conclusion}

Population health matters - not only for the evident humanitarian, legal, and society-building reasons, but also from an economic and welfare perspective. While the links between improvements in health and economic outcomes are complex, the long-run economic returns on investment in health appear large. 